It is addressed, by members of bodies concerned with the interests of chemists and chemistry, to fellowchemists, and it asks for increased collaboration between the respective bodies in the form of a federal body "to administer and guide, in accordance with the elearly-expressed will of its mémbers, all the main activities that concern chemists as professional men and working scientists". Whatever the body created for such a purpose, its chief functions would be related to: (1) publications for the exchange and dissemination of chemical knowledge; (2) scientific meetings for the discussion of problems under investigation and for the survey of specific fields of knowledge; (3) libraries, both central and regional ; (4) qualification, directed to the maintenance of a high standard of professional competence and of such methods of registration as the profession may decide, whether this registration have de jure or only de facto recognition by Government; (5) publicity, to ensure that the general public be accurately informed of what chemists and chemistry are doing and could do for the benefit of the community ; (6) social security, whereby the economic position and the legal interests of all chemists may be safeguarded; (7) social functions.

A common secretariat, a central house, and close co-operation in all centres between bodies representing chemists are believed to be necessary for the discharge of such functions. As a first step in this direction, the councils of the Chemical Society, the Society of Chemical Industry and the Institute of Chemistry are asked to consider and report immediately on how to expedite the action advocated and to obtain advice as to whether the agreement constituting the Chemical Council can be amended so as to enable the Council to function as a central organization such as that envisaged. Should it be found that the Chemical Council cannot undertake the new functions suggested, it is asked that a new federal body be set up at once, to enable chemists to take their proper part in planning and building the post-war world.

\section{The First Man-Carrying Aeroplane}

ThE Smithsonian Institution, Washington, has recently issued a pamphlet which settles a controversy that has existed for many years. It is universally acknowledged that the Wright brothers were the first to make sustained flights in a heavier-than-air machine at Kitty Hawk, North Carolina, on December 17, 1903. Earlier in the same year a machine built by Samuel Pierpont Langley was reported to have flown, and this was exhibited in the Smithsonian Museum with the label that this "Was the first man-carrying aeroplane in the history of the world capable of sustained free flight". These reported flights had never been officially observed, and in the light of later aerodynamic knowledge it was debatable whether the machine could have accomplished sustained flight under its own power. In order to settle this matter, the Institution reconditioned the machine in 1914, when it was flown successfully, but the fairness of the test was challenged on the grounds that vital alterations were introduced during this rebuilding, which improved its aerodynamic and structural characteristics sufficiently to allow it to be capable of flight. It was claimed that withput these changes, based on knowledge that was not available in 1903, the machine could not have flown. These claims have since been upheld by experts, and the Smithsonian Institution has now issued a statement on the results to Dr. Orville Wright and changed the wording of the label on the Langley machine accordingly. Although the detailed explanation has only just been issued, the description on the exhibit was altered in 1928. As a result of this misrepresentation, the Wrights lent their original machine to the Science Museum at South Kensington, where it has been exhibited for many years. The Smithsonian Institution has expressed a hope that Dr. Wright will now consider bringing it back to the United States, where it will be given "the highest place of honour in the United States National Museum".

\section{Meteors Seen in the United States}

J. Hugh PruetT has written an account of a detonating meteor (Ast. Soc. Pacific, Leaf. No. 165, Nov. 1942) under the title, "The Portland Meteor and Resulting Meteorite". The meteor was seen soon after 8 a.m. on July 2,1939 , and was not only 8 conspicuous fireball, but was also responsible for a panic among many people in Portland, Oregon, owing to the jarring of the houses while it passed over the town. From data supplied by a number of observers, it was found that the fireball became visible near the northern Oregon coast-line, and passing over northern Portland, disappeared beyond Bonneville at a height of 10 miles. It was moving in a direction opposite to that of the earth in its orbit and for this reason had a fairly high velocity-probably 40 miles a second. Next day a portion of the fireball was picked up on a farm near Washougal, fifteen miles east of Portland, and it was found that it belonged to the type of stony meteorites known as Howardites. Although search parties were organized, no other pieces were found; but it is fairly certain that the Washougal portion, weighing 225 gm., is not the only fragment which reached the earth. Howardites are described as friable and easily destroyed because the material composing them is cemented together rather loosely.

Another meteor is described by Oscar E. Monning in Sky and Telescope (November 1942). It appeared on August 7, 1942, at 9.30 c.w.T., when it was still twilight in the more western regions of its flight, and its magnitude was estimated to be -4 . When first seen it was some miles north of Shreveport, and its height then was about 80 miles. In 30 sec. it had moved to a point less than 20 miles north and east of Guymon. Its length of flight may have been 600 miles and its motion was nearly horizontal, as its total drop was about 65 miles during this long flight. It had a long tail and left an evanescent train which was $30^{\circ}$ in length as seen from some places, but it persisted for only 5-10 sec. No fragments of the meteor have been found and there were no detonations, so far as present evidence is available, but it is possible that additional information will be obtained which may assist in elucidating further important facts about this bright meteor.

\section{New Projector for. Navigational Stars}

JAMES R. BENFORD has given a description of a Bausch and Lomb artificial star projector recently installed at the United States Air Station, Pensacola, Fla., which overcomes many of the difficulties of star charts (Sky and Telescope, November 1942). The instrument is located in the centre of a hemispherical dome upon which it projects images corresponding to 145 navigational stars. The instructor and the students sit inside the dome at a level a little below 
that of the star projector, which makes the stars appear in the darkened room as points of light in a twilight sky. As the projector rotates on its axis once in 20 minutes, the stars swing slowly across the face of the dome in this time, and students are able to gain true impressions of the form, location, and interrelations of the constellations much more clearly than they can from star charts. The apparatus supplies the nearest approach to the actual study of the heavens from outdoor instruction. The latter is not always a satisfactory method when large groups. of students have to be considered, and in addition, weather conditions and the season of the year are disturbing factors. The star projector is a most important adjunct to-day in pilot training when speed is so essential.

\section{Effects of Altitude}

According to the Journal of the American Medical Association of October 24 a law was recently passed by the Senate of Argentina for the creation of a committee to supervise studies on the effects of altitude. The committee, which will consist of medical men, chemists, physicists and biologists, will form a branch of the Ministry of Internal Affairs. The field covered by the committee will be (1) biological problems in relation to the most adaptable human biotypes ; (2) working capacity, feeding, housing and climatological, hydrological, geological, zoological, botanical and physiochemical factors in relation to the life of normal men in various altitudes ; (3) pathology of altitudes, studies of diseases which may be improved by hypsotherapy, and the establishment of sanatoria and hospitals and proper altitudes for the cure of certain diseases; (4) creation of portable laboratories and establishment of experimental hypsological centres; and (5) studies of the animals and plants of different regions, the constitution of the soil and meteorological phenomena.

\section{Folk-Lore of Children's Diseases}

Aт a meeting of the Folk-Lore Society on January 20 , Dr. J. D. Rolleston read a paper on the folk-lore of children's diseases. The field is extensive, since it covers the popular conceptions of the acute exanthemata and other infectious diseases, especially whooping cough and diphtheria, venereal infections, cardiac, respiratory, alimentary disorders and isolated diseases, especially erfuresis, infantile convulsions, rickets, hernia and the supposed effects of the 'evil eye'. As regards causation, belief in the doctrine of maternal impressions is still far from extinct, although there is no scientific foundation for such a view. The recognition of astrology by orthodox medical practitioners survived until the eighteenth century, as was shown by Mead's work. The visitation of the 'evil eye' also accounted in popular estimation for many diseases, especially in countries bordering on the Mediterranean. Although a vast number of more or less irrational and inexplicable beliefs were connected with the newborn period, comparatively few of them were of medical interest. Dentition, like menstruation and pregnancy, is a normal process, and was much less frequently the cause of disease than was popularly supposed, especially by mothers who were liable to regard any of their infants' ailments as due to this cause. In like manner, tongue-tie, though often alleged by a mother to account for her child's inability to take the breast, was usually non-existent.
The belief in the superstition that venereal disease could be cured by transfer to healthy young virgins of either sex was still prevalent, and was one of the chief causes of acquired syphilis or gonorrhoea in children. Although in other departments of medical folk-lore, especially dermatology, ophthalmology and otology, prophylaxis has received much less attention from the folk than curative treatment, in the case of children's diseases, much more importance seems to have been given to prevention than in other branches of folk-medicine. Examples of the kind were the use of salt for guarding the newborn against evil demons and evil influences, the use of amulets and the administration of coral in the mother's milk.

\section{Infant Mortality in the United States}

Is a recent article on infant mortality in rural and urban areas in the United States (Public Health Rep., 57, 1494 ; 1942), Herbert J. Sommers, of the United States Public Health Service, states that the infant mortality-rate in the registration areas of the United States has been reduced by more than a half. From 1915 until 1929 the urban rate, though higher than the rural in every year, decreased more rapidly than the rural, so that in 1929 , for the first time on record, the rate was lower in urban than in rural areas, and since then the urban rate has remained lower than the rural. The rates were generally higher in the south than in other regions and rural rates were generally highest in the Middle West. The reduction in infant mortality which has taken place in cities is to be attributed to increasing emphasis being laid on the principles of sanitation, the establishment of 'well-baby' clinics, the increasing use of hospitals for delivery, the compulsory pasteurization of milk and the application of modern medical knowledge.

\section{Physical Education}

Is a lecture delivered before the Anglo-Swedish Society and published in the December issue of the Anglo-Swedish Review on the development of physical education in Great Britain and the Dominions, Miss P. Spafford, organizing secretary of the Ling Physical Education Association, said that organized physical education in Great Britain and the Dominions originated in the elementary schools, while the educational, medical and recreative gymnastics were based on Per Henrik Ling's principles. In newly built schools throughout the country conditions for physical education are excellent. Many have their own swimming bath as well as a field for games and a gymnasium. The physical education scheme in schools in Canada, South Africa, Australia and New Zealand is largely that carried out in British schools. The War has inevitably caused a certain set-back in physical education owing mainly to a shortage of gymnastics and game schooling as well as a lack of gymnastics equipment. The most popular physical activity in all the countries of the British Commonwealth is swimming. Physical training in the Services is based on the Swedish and Danish systems and is closely linked up with recent research in physiology and psychology. "Until recently there has been little or no organized physical training in the universities, although there has always been sport of various forms. There is a real need for further instructional cooperation, and further research is essential, especially into the physiological basis of exercises. 